\title{
Do cybervictimization and face-to-face victimization affect suicide ideation risk in the same way?
}

\author{
By Dr. Jessica Edwards
}

Data from a new study published in the Journal of Child Psychiatry and Psychology suggest that cybervictimization is an important risk factor for concurrent, serious suicidal ideation/attempt throughout adolescence. This risk seems to be independent of prior mental health symptoms, family hardship and face-to-face victimization.

These new findings come from a prospective birth cohort study of $>2,000$ individuals conducted by Lea Perret and colleagues. The researchers followed these individuals from birth up to 17 years-of-age and collected information on self-reported cybervictimization and face-to-face victimization at ages $12,13,15$ and 17 years. Sadly, as many as $7-16 \%$ of adolescents reported being victimized by their peers via online platforms. This cybervictimization conferred a 2-4 times higher risk of concurrent suicidal ideation/attempt compared to those who had not been victimized online, even after adjusting for face-to-face victimization and other key confounders.

The data from this analysis exposed two interesting paradigms. First, that the risk of concurrent suicidal ideation/attempt was higher in those who experienced cybervictimization than those who were victimized face-toface. Second, that face-to-face victimization was associated with suicidal ideation/attempt 2 years later. Such an association was not found for cybervictimization.

\section{Referring to:}

Perret, L.C., Orri, M., Boivin, M., Ouellet-Morin, I., Denault, A-S., Côté, S.M., Tremblay, R.E., Renaud, J., Turecki, G. \& Geoffroy, M-C. (2020), Cybervictimization in adolescence and its association with subsequent suicidal ideation/attempt beyond face-to-face victimization: a longitudinal population-based study. J. Child Psychol. Psychiatr. doi: 10.1111/jcpp.13158.

\section{Glossary:}

Cybervictimization: A form of bullying that is expressed through electronic forms of communication such as emails, texts or social media.

"This study offers a valuable insight into the short-term effects of being peer victimized in secondary school on suicidal ideation in adolescence", explains Perret. "Both face-to-face and cybervictimization were independently associated with suicidal ideation throughout adolescence suggesting that both types need to be considered as risk factors for suicidal ideation". The researchers thus explain that clinicians should systematically ask adolescents whether they have been recently cybervictimized, and whether they have had thoughts of suicide and offer appropriate interventions.

"Anti-victimization prevention efforts at the school level can potentially have an impact in reducing suicidal ideation if this relationship is causal", proposes Perret. "Some intervention strategies to reduce cybervictimization can be effective by focusing on the victims or the perpetrators, however more research is needed to determine what the best approaches are". 